\title{
Graves' Disease in Childhood: Advances in Management with Antithyroid Drug Therapy
}

\author{
Florentia Kaguelidou Jean Claude Carel Juliane Léger \\ Pediatric Endocrinology Department, Centre de Référence Maladies Endocriniennes de la Croissance, \\ Assistance Publique-Hôpitaux de Paris, Hôpital Robert Debré, Université Paris VII, Paris, France
}

\section{Key Words}

Graves' disease · Antithyroid drug therapy $\cdot$ Recurrent hyperthyroidism

\begin{abstract}
Graves' disease is the most common cause of hyperthyroidism in children. Antithyroid drug (ATD) treatment is recommended as the initial treatment, leading to a marked improvement in most symptoms within 1 month of treatment initiation. Remission is achieved in 30\% of children after a first course of ATD. Alternative treatments, such as radioactive iodine or thyroidectomy, are considered in cases of relapse, lack of compliance or ATD toxicity. The risk of relapse after a first course of ATD treatment for a median period of 2 years has been shown to be higher in patients with severe biochemical hyperthyroidism at diagnosis, young children and patients of non-Caucasian origin. Relapse risk decreases with the duration of the first course of ATD treatment, highlighting the positive impact of a long period of primary ATD treatment on outcome. The identification of predictive factors has made it possible to stratify patients according to the risk of relapse after ATD treatment, leading to improvements in patient management by facilitating the identification of
\end{abstract}

patients requiring long-term ATD or early alternative therapy. Long-term careful follow-up is needed to determine the efficacy of disease management during childhood.

Copyright $\odot 2009$ S. Karger AG, Basel

\section{Introduction}

Thyrotoxicosis is a rare but serious condition in childhood, with negative physical and behavioral effects [1]. It occurs most frequently as a consequence of Graves' disease (GD), an autoimmune disorder resulting from thyrotropin receptor stimulation by autoantibodies. Most patients are treated with antithyroid drugs (ATDs), but remission is achieved in less than $30 \%$ of children [2-6]. When relapse occurs, thyroidectomy or radioactive iodine (RAI) treatment is considered. However, the most appropriate type of management remains one of the key controversies in pediatric endocrinology and the optimal duration of ATD therapy for the induction of remission has yet to be established $[7,8]$. Reliable predictors of re-

Jean Claude Carel and Juliane Léger are members of ESPE.

\section{KARGER}

Fax +4161306 1234 E-Mail karger@karger.ch www.karger.com
(C) 2009 S. Karger AG, Basel

0301-0163/09/0716-0310\$26.00/0

Accessible online at:

www.karger.com/hre
Juliane Léger, MD

Pediatric Endocrinology Department, Hôpital Robert Debré

48 Bd Sérurier

FR-75019 Paris (France)

Tel. +33 1400323 54, Fax +33 1400324 29, E-Mail juliane.leger@rdb.aphp.fr 


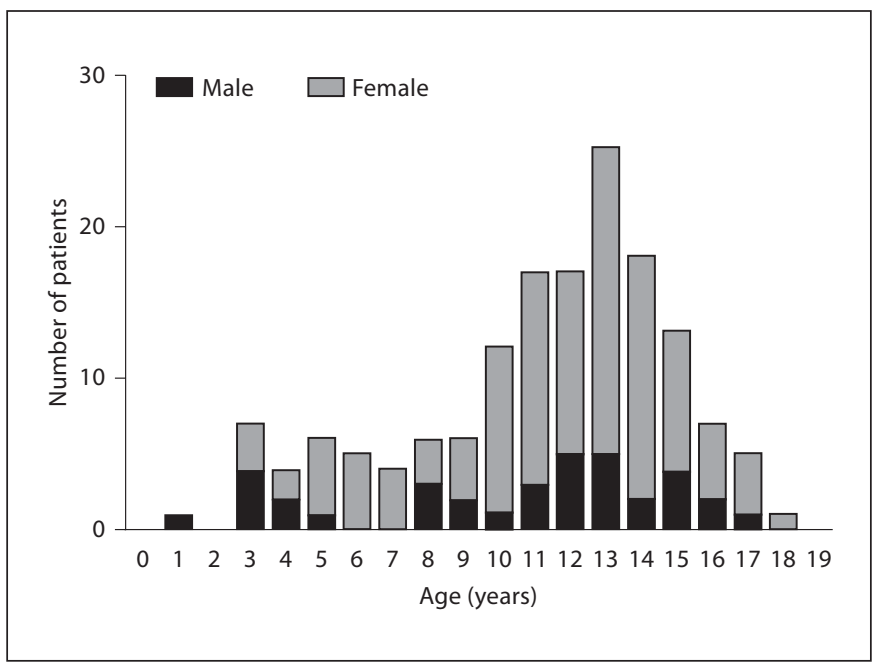

Fig. 1. Distribution of age at diagnosis of thyrotoxicosis in childhood in 154 patients with GD. The frequency of this condition increases with age, peaking in adolescence. Girls are more frequently affected than boys. Modified from Kaguelidou et al. [11] with the permission of the Endocrine Society Press.

lapse after ATD treatment would greatly improve patient management by facilitating the identification of children requiring long-term ATD or early radical treatment [911].

\section{Pathogenesis}

The cause of GD remains unclear, but it is believed to result from a complex interaction between genetic background (heredity), environmental factors and the immune system. For unknown reasons, the immune system produces an antibody (thyroid-stimulating hormone receptor antibody, TRAb) that stimulates the thyroid gland to produce excess thyroid hormone. Genetic susceptibility to the disease is thought to be polygenic. GD has been reported to be associated with the human leukocyte antigen gene on chromosome $6 \mathrm{p}$, the cytotoxic T lymphocyte antigen- 4 gene on chromosome $2 \mathrm{q} 33$ and the PTPN22 (lymphoid tyrosine phosphatase) gene on chromosome 1p13. Data from twin studies and the higher prevalence of GD in first-degree relatives of patients with this disease than in controls suggest that about $80 \%$ of the overall susceptibility to GD is determined by genetic factors $[12,13]$.

The thyroid-stimulating immunoglobulin binds to and stimulates the thyroid-stimulating hormone (TSH) receptor on the thyroid cell membrane, resulting in follicular cell growth, an increase in vascularity and the excessive synthesis and secretion of thyroid hormone. The thyroid gland typically displays lymphocytic infiltration, with T-lymphocyte abnormality and an absence of follicular destruction. $\mathrm{T}$ cells activate local inflammation and tissue remodeling by producing and releasing cytokines, leading to B-cell dysregulation and an increase in autoantibody production. An imbalance between pathogenic and regulatory $\mathrm{T}$ cells is thought to be involved in both the development of GD and its severity [14].

\section{Incidence}

GD is a rare disease in children. It occurs in about $0.02 \%$ of children $(1 / 5,000)$, accounting for $1-5 \%$ of all patients with GD. In adults, this disease affects approximately $0.5 \%$ of women [15]. In both adults and children, GD is much more frequent in female than in male subjects. It may occur at any age during childhood, but it increases in frequency with age, peaking during adolescence (fig. 1). The incidence is thought to be rising and is about 0.1 per 100,000 person-years in young children to 3 per 100,000 person-years in adolescents [16]. A frequency of up to 14 per 100,000 patient-years has been reported in Hong Kong, with no relationship to differences in iodine nutritional status $[17,18]$. GD is more frequent in children with other autoimmune conditions, and in children with a familial history of autoimmune thyroid disease.

\section{Clinical Manifestations}

Most patients present the classic symptoms and signs of hyperthyroidism. The early symptoms are often subtle, with changes in behavior, irritability, emotional lability, fatigue, nervousness, palpitations, tremor, insomnia, excessive perspiration, an increase in appetite accompanied by no weight gain or even weight loss, and diarrhea. A decline in academic performance and deterioration in attention are often associated.

The size of the thyroid gland is highly variable and the goiter may go unnoticed in patients with a slightly enlarged thyroid gland. The thyroid gland is usually symmetrically enlarged, firm, uniformly smooth and not tender. A palpable thrill may be present, reflecting the increase in blood flow through the gland. Ophthalmic abnormalities are less severe in children than in adults, 
with staring eyes, retraction of the upper lid and a wide palpebral aperture. True exophthalmos is rare in children. Thyrotoxic crisis is also an extremely rare event in childhood [19]. Other signs include tachycardia, an increase in blood pressure, precordial thrill, and an ejection murmur due to functional insufficiency of the mitral valve. Increases in height velocity, with advanced bone age, are related to the duration of hyperthyroidism. As in adults, children with GD may have a lower than normal bone mass often restored after 2 years of euthyroid state under ATD treatment [20]. Pretibial myxoedema is rare. Various symptoms are observed, and children may initially be referred to cardiologists, ophthalmologists, psychiatrists and/or gastroenterologists before being referred to an endocrinologist [19].

\section{Biochemical Confirmation of GD}

The diagnosis is confirmed by thyroid hormone measurements. TSH is undetectable in the serum $(<0.3 \mathrm{mU} / \mathrm{l})$ in all patients. Most children with hyperthyroidism have very high serum FT4 and FT3 concentrations (fig. 2). However, some patients may have normal FT4 concentrations and high FT3 concentrations - a condition termed T3 toxicosis, which may be observed at diagnosis or at times of relapse during the course of the disease. In some patients with mild hyperthyroidism and serum FT4 and FT3 levels close to the upper limit of normal values, thyrotropin-releasing hormone (TRH) tests may be carried out. In this test, the inhibition of TSH release in response to TRH stimulation confirms the diagnosis of hyperthyroidism.

TRAbs are specific to GD. They are detected in most patients, with highly variable titers (fig. 2). There is a positive correlation between serum TRAb and FT4 levels. Serum TRAb levels are significantly higher in young $(\leq 5$ years of age) patients than in older ( $>5$ years of age) patients and in patients with a severe initial clinical presentation than in those with milder clinical presentation [11]. Determination of the levels of circulating antibodies against thyroperoxidase and, in some cases, thyroglobulin may be useful for the confirmation of thyroid autoimmune disease.

\section{Thyroid Imaging}

Thyroid imaging with radioisotopes is not required for the diagnosis of GD and has been replaced by ultrasound scans. The thyroid gland is diffusely enlarged, and

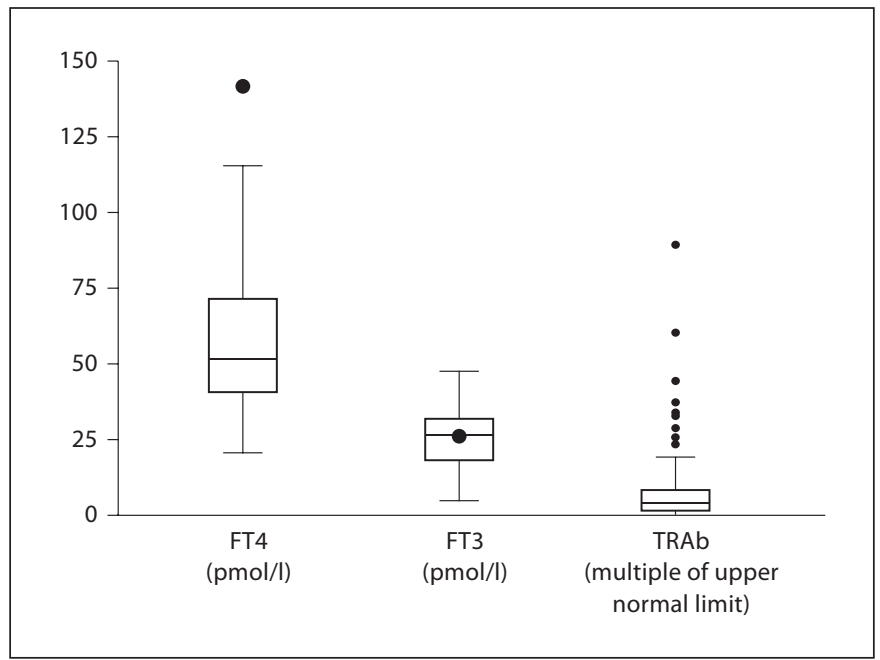

Fig. 2. Serum FT4, FT3 and TRAb levels (expressed as multiples of the upper limit for the normal range of the assay used) in a population of 154 children and adolescents at GD diagnosis. Box plots show the median values and the first and third quartiles in each group. Dots represent outliers.

often homogeneous. The gland may display normal echogenicity or may be hypoechogenic, as in thyroiditis. Diffuse parenchymal hypervascularity is observed. Highgrade hypervascularization is not observed to the same extent in patients with chronic autoimmune thyroiditis. Goiter size is variable, and the goiter may be small, moderate or large [9]. In $10 \%$ of patients, thyroid volume is normal.

\section{Management}

The optimal treatment of GD in childhood remains a matter of debate $[7,8]$, and long-term, prospective, randomized clinical studies are still required to compare treatment failure frequencies and the short- and longterm side effects of the different therapeutic options. Current treatment options include ATDs, RAI (iodine131) and subtotal or near total thyroidectomy. Relapse is defined as the presence of suppressed levels of TSH (TSH $<0.05 \mathrm{mIU} / \mathrm{l}$ ) combined with FT4 concentrations greater than $21 \mathrm{pmol} / \mathrm{l}$ or FT3 concentrations greater than 11 $\mathrm{pmol} / \mathrm{l}$. There is no specific cure for the disease and each therapeutic option has associated complications. Most patients are initially treated with ATDs. However, it is difficult to achieve long-term compliance and the rate of relapse is high in children after ATD discontinuation. 
Destruction of the gland by radioiodine treatment or surgical removal of the thyroid gland is therefore often used as an alternative. Indications for these treatments in children include relapse after an appropriate course of ATD treatment, a lack of compliance on the part of the patient or the parents and ATD toxicity. As in many rare diseases, there is currently no evidence-based strategy for the management of this disease in children, unlike in adults, in whom the disease is more frequent [21-23]. GD treatment policy varies considerably within and between countries and depends on local traditions and medical resources, the age and preference of the patient, the size of the goiter and the severity of the disease.

\section{ATD Therapy}

ATD treatment is usually recommended as the initial treatment for hyperthyroidism in children and adolescents. The most commonly used ATDs are thionamides: carbimazole and its active metabolite, methimazole (MMI), and propylthiouracil (PTU). These drugs inhibit thyroid hormone synthesis by interfering with the thyroid peroxidase-mediated iodination of tyrosine residues in thyroglobulin. PTU can also block the conversion of thyroxine to triiodothyronine, whereas carbimazole or MMI cannot. All thionamides are associated with minor reactions (rash, urticaria, arthralgia, gastrointestinal problems) in about $5-25 \%$ of cases. A serious complication of ATD treatment is agranulocytosis, with an observed frequency between 0.2 and $0.5 \%$ for both drugs. Other major rare side effects, including drug-induced hepatitis and antibody-positive related vasculitis, are more commonly observed with PTU than carbimazole or MMI treatment. Indeed, according to a recent NIH report [24], the frequency of PTU-induced hepatitis can be as high as $25 \%$, although severe hepatitis is probably less than $1 \%$. Thus, PTU is not recommended as a first-line treatment for children [25]. The frequency of side effects may be dose-related and that of severe side effects is very low in patients receiving carbimazole or MMI at a dose of less than $10 \mathrm{mg} / \mathrm{day}$ [22]. Moreover, they are more effective in the short term than PTU [26]. Carbimazole or MMI also presents a major advantage over PTU in terms of compliance, as has a longer half-life and is effective when given as a single daily dose. The initial starting dose of PTU is $5-10 \mathrm{mg} / \mathrm{kg} /$ day, with a maximum of $300 \mathrm{mg} /$ day in three equal doses, whereas that of carbimazole or MMI is $0.5-1 \mathrm{mg} / \mathrm{kg} / \mathrm{day}$, with a maximal dose of $30 \mathrm{mg}$ per day. After 2-4 weeks, when thyroid hormone secretion is effectively blocked and thyroid hormone levels have normalized, the initial dose is gradually reduced by
$30-50 \%$ [16]. No additional benefit accrues from the maintenance of a high dose of ATD, administered with replacement doses of L-thyroxine. Recent studies have even suggested that high-dose therapy may be harmful, because the frequency of side effects is dose-dependent. There is also currently no rationale for the use of L-thyroxine in combination with ATDs to enhance remission rates [22]. Additional treatment with beta-blockers (except in patients with asthma or cardiac failure) during the first 2 weeks of management may help to reduce the patient's symptoms. This treatment can be given orally twice daily, at a dose of $2 \mathrm{mg} / \mathrm{kg} /$ day, and stopped when the patient becomes euthyroid.

GD remission on ATD therapy is linked to the restoration of euthyroidism rather than the immunosuppressive effects of the drugs. Hyperthyroidism itself has been shown to worsen the autoimmune aberration, and autoimmunity leads to the generation of more TSH receptor antibodies and a worsening of hyperthyroidism. Once this cycle is broken by ATD treatment rendering the patient euthyroid, the patient may experience gradual remission of the disease [27]. More prolonged use of ATD (at least 2-4 years) in children than in adults may be required to achieve remission. Compliance is therefore an important issue in the management of these children and should be improved by educational strategies [28]. However, the inhibition of autoantibodies obtained on treatment is difficult to predict, probably because the treatment does not target B cells or autoantibodies directly. B lymphocytes are important self-antigen-presenting cells and precursors of antibody-secreting plasma cells. Temporary B-lymphocyte depletion with the monoclonal antibody rituximab may therefore efficiently decrease or abolish the production of TRAb antibodies. Large clinical trials of this treatment are currently required [2931].

Less than $30 \%$ of children achieve lasting remission after about 24 months of ATD [3-6, 9-11]. For the remaining patients, near-total thyroidectomy or radioiodine therapy are the definitive therapeutic options, but both carry a high risk of permanent hypothyroidism. Unfortunately, prospective randomized trials evaluating the efficacy of short- and long-term ATD therapy for increasing the remission rate in children are still lacking, and further studies are required to increase our knowledge of ATD treatment in children.

\section{Iodine Treatment}

RAI treatment is effective in children with hyperthyroidism due to GD, and most patients can be successfully 
treated with a single oral dose leading to radioiodine-mediated destruction. Radioiodine therapy has also a particular effect on thyroid autoimmunity. Larger doses (220-275 $\mu \mathrm{Ci} / \mathrm{g}$, corresponding to about $250 \mathrm{~Gy}$ ) should be preferred over smaller doses of ${ }^{131} \mathrm{I}$ [32]. RAI treatment carries a small risk of aggravating thyroid eye disease, particularly in smokers. There is no evidence of reproductive dysfunction or higher frequencies of abnormalities in the offspring of treated patients [33]. RAI is absolutely contraindicated during pregnancy and breast-feeding. RAI should also be avoided in very young children because of an increased potential risk of neoplasia. Concerns about potential thyroid malignancy, hyperparathyroidism and mortality rates have highlighted the need for a large, randomized control study with long-term followup to settle this issue definitively [34]. Hypothyroidism is likely to occur after treatment, and appropriate doses of L-thyroxine must therefore be administered throughout the patient's life.

\section{Surgical Treatment}

Total (or near total) thyroidectomy is often preferred to subtotal (or partial) thyroidectomy, to reduce the risk of recurrent hyperthyroidism [8]. The vascularity of the gland is decreased by adding iodine to ATD (5-10 drops of Lugol's solution) for 1 week before surgery [35]. L-Thyroxine replacement therapy should be initiated within days of surgery and the patient should be subject to longterm follow-up. Complications, such as hypoparathyroidism, vocal cord palsy and keloid formation, are rare for operations performed by a pediatric surgeon with extensive experience. For patients with recurrent hyperthyroidism after surgery, RAI treatment is recommended because the risk of complications is higher for a second operation [8].

This radical option is often recommended in patients with a large goiter or with ophthalmopathy. For other cases, there is still some debate about whether RAI treatment or surgical ablation should be preferred as the definitive treatment for pediatric GD $[7,8]$.

\section{Long-Term Outcome}

\section{Remission Rate}

About 30\% of children treated with ATDs achieve remission lasting at least 2 years, whereas ATD treatment results in long-term remission in about $40-60 \%$ of adult patients $[3-6,9-11,36]$. Consequently, the overall frequency of relapse is higher in children than in adults.
About $75 \%$ of patients relapse within 6 months of the end of drug treatment, whereas only $10 \%$ relapse after 18 months.

\section{Predictive Factors for Relapse}

Methods for identifying patients unlikely to be in remission of the disease after drug treatment discontinuation would greatly improve patient management, as they would facilitate the identification of patients requiring long-term ATD or early alternative definitive treatment. Previous studies had their limitations but evaluated age, goiter size, decrease in body mass index and severity of biochemical hyperthyroidism at onset, slow achievement of euthyroid status after ATD initiation, TRAb levels at onset and at the end of treatment, and the duration of medical treatment as predictive markers of GD relapse during childhood [2, 6, 9, 10, 37-39]. However, all but two $[10,11]$ of these studies were retrospective and none has led to widespread changes in clinical practice. A recent prospective study [11] showed that the risk of relapse is higher for patients of non-Caucasian origin, young patients, and patients with severe disease at diagnosis, as demonstrated by high serum TRAb and FT4 levels. NonCaucasian patients were found to be 2.5 times more likely to suffer a relapse than Caucasian patients. Similarly, a 10 -point increase in serum FT4 levels and a 10-unit increase in the multiple of the upper limit of the normal range for serum TRAb levels at diagnosis led to 18 and $21 \%$ increases, respectively, in the risk of relapse. Relapse was less likely in older children, with a decrease in risk of $26 \%$ for every 5 -year increase in age. Moreover, relapse risk decreased with increasing duration of the first course of ATD, with a $43 \%$ decrease in relapse risk for every additional 12 months of treatment. These results highlight the positive impact of a long period of primary ATD treatment on outcome, resulting in the minimization of thyroid autoimmunity and recurrence of the disease.

Based on the findings of this study, a prognostic score has been developed, allowing the identification of three different risk groups at diagnosis of childhood GD, defined on the basis of clinical and biological characteristics at diagnosis and intended duration of ATD treatment: group A (low-risk group, score from 0 to $3,38 \%$ of cases), group B (intermediate-risk group, score from 4 to 7, 47\% of cases) and group C (high-risk group, score from 8 to 11, $15 \%$ of cases; fig. 3). The patients in risk group A have a predicted 2-year relapse rate of $46 \%$, those in group B have a relapse rate of $77 \%$, whereas those in group $\mathrm{C}$ have relapse rates as high as 98\% 2 years after the end of ATD treatment [11]. This score requires validation by applica- 


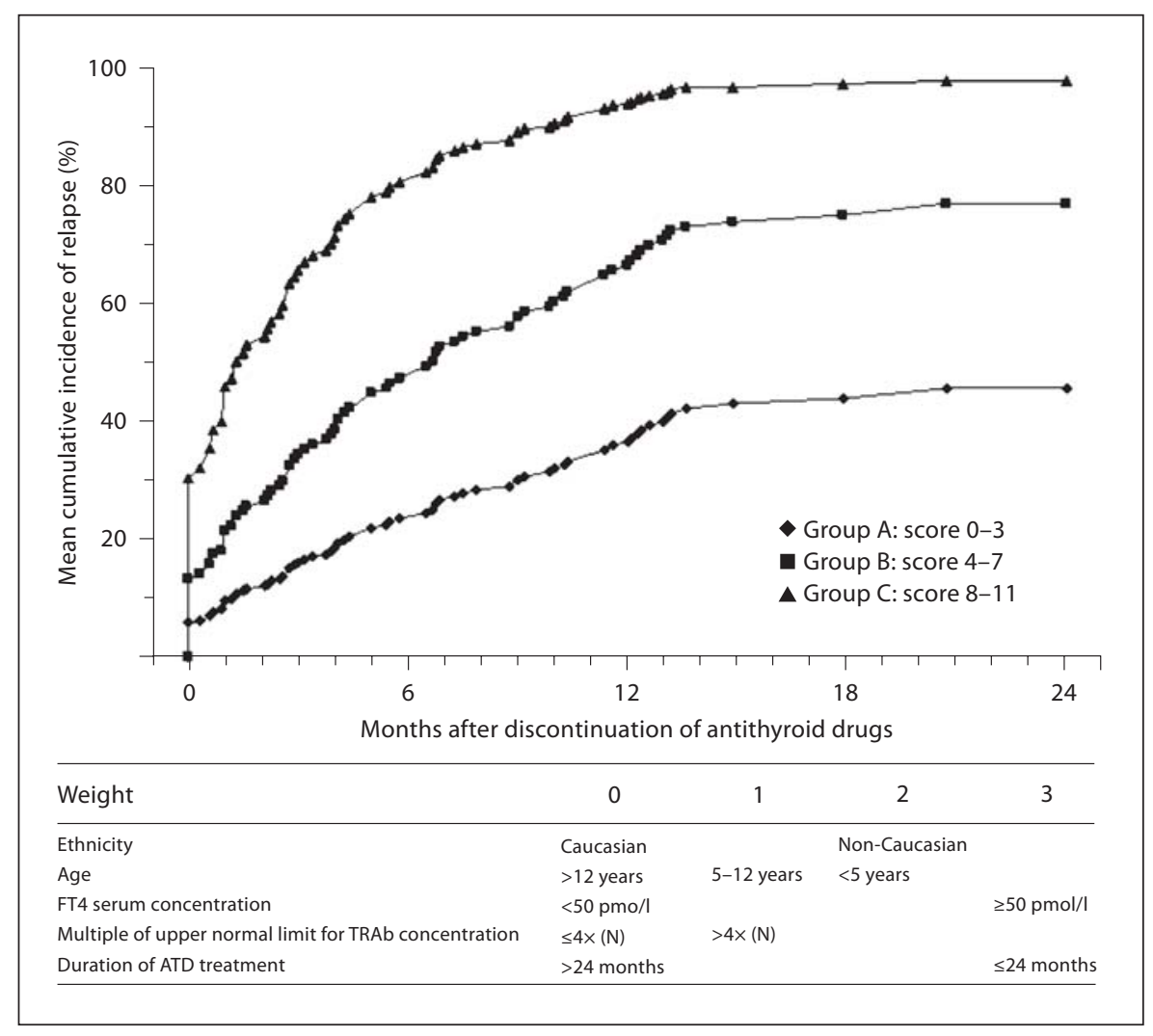

Fig. 3. Mean cumulative incidence of relapse in the 2 years after treatment discontinuation for the 3 risk groups of children with GD. The prognostic score is defined as the weighted sum of the clinical (Caucasian $=0$, non-Caucasian $=2$; age $>12$ years $=0$, age ranged from 5 to 12 years $=1$, age $<5$ years $=2$ ) and laboratory $[\mathrm{FT} 4<50 \mathrm{pmol} / \mathrm{l}=0, \mathrm{FT} 4 \geq 50 \mathrm{pmol} / \mathrm{l}=3$; multiple of upper normal limit for TRAb levels $\leq 4 \times(\mathrm{N})=0,>4 \times(\mathrm{N})=1$ ] features at initial presentation and the intended duration of ATD treatment (duration $>2$ years $=0, \leq 2$ years $=3$ ). For each patient, score may range from 0 to 11 . We present two examples of the use of this score in clinical practice. Example 1: A 15 -year-old (0 points) Caucasian (0 points) adolescent with a serum FT4 concentration of 55 $\mathrm{pmol} / \mathrm{l}$ ( 3 points) and TRAb levels 3 times the upper limit of the assay's normal range at diagnosis ( 0 points). If this child is treated for less than 2 years, then his total score is 7 (intermedi-

tion to another population of children with GD, but its use could potentially be of considerable benefit for patient counseling and for guiding appropriate therapeutic decisions. Other factors such as genetic background, sex, iodine intake, smoking and pregnancy are thought to modulate individual responsiveness in adults [36, 40-43].

\section{Pregnancy}

Regular monitoring of thyroid function and serum TRAb levels during pregnancy is mandatory. Both types ate-risk group, approximately $80 \%$ risk of relapse in the 2 years after stopping treatment), whereas if he is treated for more than 2 years, then his total score is 3 (low-risk group, more than a one in two chance of not relapsing in the 2 years after stopping treatment). Example 2: A 2-year-old (2 points) non-Caucasian (2 points) child with a serum FT4 concentration of $55 \mathrm{pmol} / \mathrm{l}(3$ points) and TRAb levels 5 times the upper limit of the assay's normal range at diagnosis (1 point). This child has practically no chance of achieving remission after treatment discontinuation, even if correctly treated for more than 2 years (score $=8$ or 11, depending on the duration of treatment). In this group of children, definitive options should be considered when the child is of an appropriate age for radioiodine therapy or surgery. Modified from Kaguelidou et al. [11] with the permission of the Endocrine Society Press. possible risk of congenital malformations, such as aplasia cutis and choanal/esophageal atresia, with carbimazole. The lowest dose of ATD should be used. GD generally improves during the second half of pregnancy allowing ATD therapy to be decreased. The early diagnosis and treatment of fetal hyperthyroidism or hypothyroidism are crucial and highlight the importance of TRAb determination throughout pregnancy, in women with a history of GD. In fetuses with goiter, the main clinical issue 
is determining whether the cause is maternal treatment with ATD at levels appropriate for achieving normal maternal thyroid function but inappropriate and excessive for the fetus, leading to fetal hypothyroidism, or fetal thyroid stimulation by maternal GD, with the presence of TRAbs stimulating the fetal thyroid gland and causing hyperthyroidism in the fetus and during the first weeks of life [44].

\section{Quality of Life}

Negative consequences for the patients' health-related quality of life during and after treatment, even after 1421 years and particularly as concerns mental performance and 'vitality', have been demonstrated in adult patients with GD. These problems do not seem to be accounted for by the patient's thyroid hormone status during followup. However, the mode of treatment, whether drug-based, surgical or based on the use of radioiodine, has been shown to have little impact on health-related quality of life in the long term [45]. These aspects have not been studied in children, but it would seem prudent to monitor subjects with hyperthyroidism in childhood in the longer term, not only for the thyroid disease but also for neuropsychological, emotional and/or behavioral function.

In conclusion, the management of GD in children could be improved by the use of a predictive score, with ATD treatment duration adjusted as a function of the patient's characteristics at initial presentation. However, although longer periods of primary ATD treatment are required in children than in adults, the optimal duration of medical treatment remains unknown and should be evaluated in large, prospective, randomized trials in a pediatric population. Furthermore, children and adolescents require appropriate parental and professional support enabling them to take responsibility for their own treatment, improving compliance with treatment and control of hyperthyroidism. Educational strategies favoring this approach should be developed. Long-term follow-up until adulthood is required, even after the discontinuation of drug therapy and after other alternative treatments (radioiodine or surgery), to determine the efficacy of GD management during childhood and its impact on health outcome.

\section{References}

1 Weetman AP: Graves' disease. N Engl J Med 2000;343:1236-1248.

2 Collen RJ, Landaw EM, Kaplan SA, Lippe $\mathrm{BM}$ : Remission rates of children and adolescents with thyrotoxicosis treated with antithyroid drugs. Pediatrics 1980;65:550-556.

3 Hamburger JI: Management of hyperthyroidism in children and adolescents. J Clin Endocrinol Metab 1985;60:1019-1024.

4 Zimmerman D, Gan-Gaisano M: Hyperthyroidism in children and adolescents. Pediatr Clin North Am 1990;37:1273-1295.

5 Boiko J, Leger J, Raux-Demay MC, Cabrol S, Le Bouc Y, Czernichow P: Maladie de Basedow chez l'enfant: aspects cliniques et évolutifs. Arch Pediatr 1998;5:722-730.

-6 Lazar L, Kalter-Leibovici O, Pertzelan A, Weintrob N, Josefsberg Z, Phillip M: Thyrotoxicosis in prepubertal children compared with pubertal and postpubertal patients. J Clin Endocrinol Metab 2000;85:3678-3682.

7 Rivkees SA, Dinauer C: An optimal treatment for pediatric Graves' disease is radioiodine. J Clin Endocrinol Metab 2007;92:797800.

8 Lee JA, Grumbach MM, Clark OH: The optimal treatment for pediatric Graves' disease is surgery. J Clin Endocrinol Metab 2007;92: 801-803.
Glaser NS, Styne DM: Predictors of early remission of hyperthyroidism in children. J Clin Endocrinol Metab 1997;82:1719-1726.

10 Glaser NS, Styne DM: Predicting the likelihood of remission in children with Graves' disease: a prospective, multicenter study. Pediatrics 2008;121:e481-e488.

11 Kaguelidou F, Alberti C, Castanet M, Guitteny MA, Czernichow P, Leger J: Predictors of autoimmune hyperthyroidism relapse in children after discontinuation of antithyroid drug treatment. J Clin Endocrinol Metab 2008;93:3817-3826.

12 Brix TH, Kyvik KO, Hegedus L: What is the evidence of genetic factors in the etiology of Graves' disease? A brief review. Thyroid 1998;8:727-734.

13 Brix TH, Kyvik KO, Christensen K, Hegedus L: Evidence for a major role of heredity in Graves' disease: a population-based study of two Danish twin cohorts. J Clin Endocrinol Metab 2001;86:930-934.

14 Saitoh O, Nagayama Y: Regulation of Graves' hyperthyroidism with naturally occurring $\mathrm{CD} 4+\mathrm{CD} 25+$ regulatory $\mathrm{T}$ cells in a mouse model. Endocrinology 2006; 147:2417-2422.

15 Cooper DS: Hyperthyroidism. Lancet 2003; 362:459-468.
16 Lavard L, Ranlov I, Perrild H, Andersen O, Jacobsen BB: Incidence of juvenile thyrotoxicosis in Denmark, 1982-1988. A nationwide study. Eur J Endocrinol 1994;130:565-568.

17 Wong GW, Cheng PS: Increasing incidence of childhood Graves' disease in Hong Kong: a follow-up study. Clin Endocrinol (Oxf) 2001;54:547-550.

18 Yang F, Shan Z, Teng X, Li Y, Guan H, Chong W, Teng D, Yu X, Fan C, Dai H, Yu Y, Yang R, Li J, Chen Y, Zhao D, Mao J, Teng W: Chronic iodine excess does not increase the incidence of hyperthyroidism: a prospective community-based epidemiological survey in China. Eur J Endocrinol 2007;156:403408 .

19 Birrell G, Cheetham T: Juvenile thyrotoxicosis; can we do better? Arch Dis Child 2004; 89:745-750.

20 Lucidarme N, Ruiz JC, Czernichow P, Leger $\mathrm{J}$ : Reduced bone mineral density at diagnosis and bone mineral recovery during treatment in children with Graves' disease. J Pediatr 2000;137:56-62.

21 Cooper DS: Antithyroid drugs in the management of patients with Graves' disease: an evidence-based approach to therapeutic controversies. J Clin Endocrinol Metab 2003; 88:3474-3481.

22 Cooper DS: Antithyroid drugs. N Engl J Med 2005;352:905-917. 
23 Brent GA: Clinical practice. Graves' disease. N Engl J Med 2008;358:2594-2605.

24 http://bpca.nichd.nih.gov/outreach/upload/ hepatic-toxicity-10-28-08-final-final-0109-09.pdf.

-25 Sato H, Hattori M, Fujieda M, Sugihara S, Inomata $\mathrm{H}$, Hoshi $\mathrm{M}$, Miyamoto S: High prevalence of antineutrophil cytoplasmic antibody positivity in childhood onset Graves' disease treated with propylthiouracil. J Clin Endocrinol Metab 2000;85:42704273.

-26 Nakamura H, Noh JY, Itoh K, Fukata S, Miyauchi A, Hamada N: Comparison of methimazole and propylthiouracil in patients with hyperthyroidism caused by Graves' disease. J Clin Endocrinol Metab 2007;92:21572162.

27 Laurberg P: Remission of Graves' disease during anti-thyroid drug therapy. Time to reconsider the mechanism? Eur J Endocrinol 2006;155:783-786.

28 Costello I, Wong IC, Nunn AJ: A literature review to identify interventions to improve the use of medicines in children. Child Care Health Dev 2004;30:647-665.

-29 Wang SH, Baker JR Jr: Targeting B cells in Graves' disease. Endocrinology 2006; 147: 4559-4560.

- 30 El Fassi D, Nielsen CH, Hasselbalch HC, Hegedus L: The rationale for $\mathrm{B}$ lymphocyte depletion in Graves' disease. Monoclonal antiCD20 antibody therapy as a novel treatment option. Eur J Endocrinol 2006;154:623-632.

- 31 El Fassi D, Nielsen CH, Bonnema SJ, Hasselbalch HC, Hegedus L: B lymphocyte depletion with the monoclonal antibody rituximab in Graves' disease: a controlled pilot study. J Clin Endocrinol Metab 2007;92: 1769-1772.
-32 Rivkees SA: The management of hyperthyroidism in children with emphasis on the use of radioactive iodine. Pediatr Endocrinol Rev 2003;1(suppl 2):212-221; discussion 221-212.

33 Read CH Jr, Tansey MJ, Menda Y: A 36-year retrospective analysis of the efficacy and safety of radioactive iodine in treating young Graves' patients. J Clin Endocrinol Metab 2004;89:4229-4233.

34 Metso S, Jaatinen P, Huhtala H, Auvinen A, Oksala H, Salmi J: Increased cardiovascular and cancer mortality after radioiodine treatment for hyperthyroidism. J Clin Endocrinol Metab 2007;92:2190-2196.

-35 Erbil Y, Ozluk Y, Giris M, Salmaslioglu A, Issever H, Barbaros U, Kapran Y, Ozarmagan S, Tezelman S: Effect of Lugol solution on thyroid gland blood flow and microvessel density in the patients with Graves' disease. J Clin Endocrinol Metab 2007;92:21822189.

36 Weetman AP: Graves' hyperthyroidism: how long should antithyroid drug therapy be continued to achieve remission? Nat Clin Pract Endocrinol Metab 2006;2:2-3.

>37 Lippe BM, Landaw EM, Kaplan SA: Hyperthyroidism in children treated with long term medical therapy: twenty-five percent remission every 2 years. J Clin Endocrinol Metab 1987;64:1241-1245.

38 Shulman DI, Muhar I, Jorgensen EV, Diamond FB, Bercu BB, Root AW: Autoimmune hyperthyroidism in prepubertal children and adolescents: comparison of clinical and biochemical features at diagnosis and responses to medical therapy. Thyroid 1997; 755-760.
39 Mussa GC, Corrias A, Silvestro L, Battan E, Mostert M, Mussa F, Pellegrino D: Factors at onset predictive of lasting remission in pediatric patients with Graves' disease followed for at least three years. J Pediatr Endocrinol Metab 1999;12:537-541.

40 Allahabadia A, Daykin J, Holder RL, Sheppard MC, Gough SC, Franklyn JA: Age and gender predict the outcome of treatment for Graves' hyperthyroidism. J Clin Endocrinol Metab 2000;85:1038-1042.

-41 Nedrebo BG, Holm PI, Uhlving S, Sorheim JI, Skeie S, Eide GE, Husebye ES, Lien EA, Aanderud S: Predictors of outcome and comparison of different drug regimens for the prevention of relapse in patients with Graves' disease. Eur J Endocrinol 2002;147:583589.

42 Kim TY, Park YJ, Park DJ, Chung HK, Kim WB, Kohn LD, Cho BY: Epitope heterogeneity of thyroid-stimulating antibodies predicts long-term outcome in Graves' patients treated with antithyroid drugs. J Clin Endocrinol Metab 2003;88:117-124.

$\checkmark 43$ Rotondi M, Chiovato L, Romagnani S, Serio M, Romagnani P: Role of chemokines in endocrine autoimmune diseases. Endocr Rev 2007;28:492-520.

44 Luton D, Le Gac I, Vuillard E, Castanet M, Guibourdenche J, Noel M, Toubert ME, Leger J, Boissinot C, Schlageter MH, Garel C, Tebeka B, Oury JF, Czernichow P, Polak M: Management of Graves' disease during pregnancy: the key role of fetal thyroid gland monitoring. J Clin Endocrinol Metab 2005; 90:6093-6098.

45 Abraham-Nordling M, Wallin G, Lundell G, Torring O: Thyroid hormone state and quality of life at long-term follow-up after randomized treatment of Graves' disease. Eur J Endocrinol 2007;156:173-179. 